\title{
Lower Cortisol Levels in Depressed Patients with Comorbid Post-Traumatic Stress Disorder
}

\author{
MA Oquendo*,', G Echavarria', HC Galfalvy', MF Grunebaum', A Burke', A Barrera', TB Cooper', \\ KM Malone' and J John Mann' \\ 'Department of Neuroscience, New York State Psychiatric Institute, Columbia University, New York, NY, USA
}

\begin{abstract}
Post-traumatic stress disorder (PTSD) is often comorbid with major depressive episodes (MDEs) and both conditions carry a higher rate of suicidal behavior. Hypothalamic-pituitary-adrenal (HPA) axis and serotonin abnormalities are associated with both conditions and suicidal behavior, but their inter-relation is not known. We determined cortisol response to placebo or fenfluramine in MDE, MDE and PTSD (MDE+PTSD), and healthy volunteers ( $H V s)$ and examined the relation of cortisol responses to suicidal behavior. A total of 58 medication-free patients with MDE ( 3 had MDE+PTSD) and $24 \mathrm{HVs}$ were studied. They received placebo on the first day and fenfluramine on the second day. Cortisol levels were drawn before challenge and for $5 \mathrm{~h}$ thereafter. The MDE+PTSD group had the lowest plasma cortisol, the MDE group had the highest, and HVs had intermediate levels. There were no group differences in cortisol response to fenfluramine. Suicidal behavior, sex, and childhood history of abuse were not predictors of baseline or postchallenge plasma cortisol. Cortisol levels increased with age. This study finds elevated cortisol levels in MDE and is the first report of lower cortisol levels in MDE+PTSD. The findings underscore the impact of comorbidity of PTSD with MDE and highlight the importance of considering comorbidity in psychobiology.

Neuropsychopharmacology (2003) 28, 59I-598. doi: I 0. I038/sj.npp. I 300050
\end{abstract}

Keywords: post-traumatic stress disorder; major depression; cortisol; suicidal behavior; childhood abuse; fenfluramine; serotonin

\section{INTRODUCTION}

Post-traumatic stress disorder (PTSD) develops in $15-25 \%$ of those exposed to trauma (Davidson, 1995; Maes et al, 2000). It is associated with significant morbidity and mortality, and increases the risk for suicidal behavior as much as 14-fold (Davidson et al, 1991). PTSD is often comorbid with major depressive episodes (MDEs), with a significant overlap in the symptoms required for diagnosis based on DSM IV criteria. Major depression, PTSD and suicidal acts often are present in the same individual, and are all associated with Hypothalamic-pituitary-adrenal (HPA) axis dysfunction. Since MDE and suicide are associated with HPA overactivity and PTSD is associated with HPA underactivity (Carroll, 1982; Yehuda, 2001), HPA axis function in comorbid MDE and PTSD, and its interaction with history of suicidal acts, is of interest.

\footnotetext{
*Correspondence: Dr MA Oquendo, Department of Neuroscience, New York State Psychiatric Institute, Columbia University, 1051 Riverside Drive Unit 42, New York, NY 10032, USA, Tel: +1 212 543 5835, Fax: + I 2125436017 ,

E-mail: moquendo@neuron.cpmc.columbia.edu

Received 2 May 2002; revised 31 July 2002; accepted 2 August 2002 Online publication: 19 August 2002 at http://www.acnp.org/citations/ Npp081902370
}

Studies of PTSD have found low levels of $24 \mathrm{~h}$ urinary cortisol (Yehuda et al, 1990; Mason et al, 1986), low plasma cortisol (Yehuda et al, 1995; Kanter et al, 2001), and hypersuppression of cortisol in dexamethasone suppression tests (DSTs) (Reist et al, 1995; Stein et al, 1997). In contrast, elevated cortisol levels have been reported in MDE (Westrin et al, 1999), and about half of the in-patients with MDE fail to suppress cortisol secretion after dexamethasone (Brown et al, 1987; Duval et al, 2001; Yehuda et al, 1996; Halbreich et al, 1989). Most (Coryell and Schlesser, 2001; Meltzer et al, 1984; Norman et al, 1990; Oei et al, 1990; Inder et al, 1997; Roy, 1992), but not all, (Cleare et al, 1996; Duval et al, 2001; Westrin et al, 1999) studies of HPA axis in suicidal behavior suggest that there is elevation of cortisol or dexamethasone resistance in future suicide completers. Some of these discrepancies may be related to the spectrum of suicidal behavior that is assessed, such that suicidal ideation or the presence of attempts in a subject's history may have less of an effect on cortisol secretion than the violence of the attempt (Roy, 1992) or ultimate suicide completion (Coryell and Schlesser, 2001).

The HPA axis has a close bidirectional relation with the serotonergic system (Meijer and De Kloet, 1998). For example, agonism of the 5HT1A receptor with ipsapirone results in secretion of adrenocorticotropin hormone (ACTH) and cortisol, as occurs with fenfluramine, a less selective agent (Lesch et al, 1990). On the other hand, 
hippocampal 5HT1A binding is observed to be elevated in rats in response to cortisol surges in the context of acute stress (Magarinos and McEwen, 1995) and decreased in response to chronic stress (Watanabe et al, 1993). Changes in 5HT2A binding in rat cortex as a consequence of stress have been described as well (Brown et al, 1999).

Despite the frequent co-occurrence of PTSD and MDE, we could find only one study of the HPA axis when these conditions are comorbid (Halbreich et al, 1989). That study found a normal DST response and plasma cortisol in MDE and PTSD, in contrast with evidence of higher plasma cortisol in those with MDE alone. A computer-assisted literature search did not uncover any studies of the biology of MDE, PTSD, and suicidal behavior.

It is possible that the variability in rates of suicidal behavior in different depressed populations contributes to the inconsistency of findings regarding cortisol levels in studies of MDE. Similarly, the rate of PTSD in depressed populations is likely to differ from study to study also contributing to the inconsistency of findings, especially in depression. Therefore, in order to examine the relation of PTSD, MDE, and suicidal behavior to HPA axis response and to evaluate the relation of serotonergic function to HPA function, we measured cortisol levels over a period of $5 \mathrm{~h}$ and following a placebo, and a fenfluramine challenge. Serotonin causes release of ACTH from the anterior pituitary. We compared patients with MDE, MDE and PTSD (MDE+PTSD), and healthy volunteers (HVs). We also examined the relation of plasma cortisol to reported childhood abuse and to suicidal behavior in the patient groups. We hypothesized that those with MDE+PTSD would have lower levels of cortisol compared with MDE alone and HVs. For exploratory analyses, we evaluated the relations of suicidal behavior, childhood abuse, melancholia, psychosis, and severity of depression to cortisol levels on placebo and fenfluramine.

\section{METHODS}

\section{Subjects}

A total of 58 patients with MDE were diagnosed based on the Structured Clinical Interview for DSM-III-R; Patient version (SCID-P) (American Psychiatric Association Task Force, 1987) was entered into the study. Of the 58 patients, 13 had a lifetime history of PTSD and seven had PTSD at the time of study. All patients (MDE and MDE+PTSD) were medication free for a minimum of 14 days (6 weeks in the case of fluoxetine and 1 month in the case of oral antipsychotics) prior to study. Patients were allowed up to $3 \mathrm{mg}$ daily of lorazepam during the washout phase, but not in the 3 days prior to the study. HV $(n=24)$ were recruited through advertising and were free of psychiatric diagnoses based on the SCID-NP (nonpatient version). All subjects were free of medical illnesses based on history, physical examination, and laboratory tests. Pregnant females were excluded. Premenopausal female subjects were studied within 5 days after onset of menses. All subjects gave written informed consent as approved by the Institutional Review Board.

\section{Data Collection}

Demographic information, including childhood experiences such as a history of physical or sexual abuse before age 15, was collected on the Columbia Baseline Demographic Form. Psychiatric symptoms were rated with the 17-item Hamilton Depression Rating Scale (HDRS) (Hamilton, 1960), the Beck Depression Inventory (Beck et al, 1961), and the Brief Psychiatric Rating Scale (BPRS) (Overall and Gorham, 1962). The items of agitation, psychic anxiety, somatic anxiety, hypochondriasis from the HDRS, anxiety, somatic concern, and tension from the BPRS were used to measure the presence of anxiety symptoms. Lifetime history of suicide attempts was recorded on the Columbia Suicide History form. Suicidal ideation and behavior were quantified with the Beck Scale for Suicidal Ideation (SSI) (Beck et al, 1979), Suicide Intent Scale (SIS) (Beck et al, 1975) measuring intent at the time of the most lethal attempt, and Beck's Medical Lethality Scale (Beck et al, 1975), which scores the degree of medical damage caused by their most lethal attempt. Aggressive/impulsive traits were rated by the Barratt Impulsivity Scale (BIS) (Barratt, 1965) and BrownGoodwin Aggression Scale (BG) (Brown et al, 1979). Axis II diagnoses were made by Structured Clinical Interview for DSM-III-R SCID for Axis II (First et al, 1996). These scales were utilized because depression severity, anxiety, suicidal acts, aggression, and personality disorders have all been reported to be associated with abnormalities of the HPA axis, serotonergic function, or both.

\section{Plasma Cortisol Studies}

Subjects were studied on two consecutive days after fasting from midnight and throughout the test. They received placebo on the first day and fenfluramine on the second day in a single blind design. On each day, an intravenous catheter was inserted at approximately 8:00 am and an infusion of $5 \%$ dextrose and $0.45 \%$ saline was started. Cortisol levels were drawn $15 \mathrm{~min}$ and immediately before placebo or fenfluramine administration to ascertain baseline levels. An oral dose of approximately $0.8 \mathrm{mg} / \mathrm{kg}$ of dlfenfluramine (or identical pill containing placebo) was administered at 9:00 am. Cortisol, fenfluramine, and norfenfluramine levels were drawn hourly for $5 \mathrm{~h}$ thereafter. Subjects were awake during the procedure. Cortisol levels were ascertained by radioimmunoassay after denaturation of the binding proteins by heat. Anti-rabbit globulin serum, in conjunction with polyethylene glycol, was used for separation of the bound and free fractions. All samples were assayed in duplicate. The interassay coefficient of variation was $6.0,3.9$, and 2.9 at concentrations of $3.1,19.3$, and $32.7 \mu \mathrm{g} / \mathrm{dl}$, respectively. Fenfluramine and norfenfluramine levels were measured by a gas-liquid chromatography method (Myers et al, 1994; Krebs et al, 1984).

\section{Statistical Analysis}

Relations between demographic and clinical variables were examined using the $\chi^{2}$ statistic for independence and analysis of variance. Cortisol responses to placebo and fenfluramine for each of the three groups (MDE, $\mathrm{MDE}+\mathrm{PTSD}$, and HV) were compared using general linear 
models for repeated measures, with lifetime diagnostic group, age, sex, depression severity, anxiety severity, suicide attempt status, number of suicide attempts, lethality of most severe suicide attempt, presence of childhood history of abuse, psychosis, and melancholia as predictors. Interactions between age, sex, and the other categorical variables were also explored. Similar models were built to establish the effect of current PTSD on cortisol levels. Drug levels were calculated as the sum of fenfluramine and norfenfluramine blood levels at each hour, and compared in the three groups using a generalized linear model for repeated measures.

\section{RESULTS}

The three groups, HV, MDE, and MDE+PTSD, did not differ with regard to major demographic indices such as age $(42 \pm 17 ; 41 \pm 12,38 \pm 11$, respectively: $F=0.33$, $\mathrm{df}=2, p<0.72)$, race (\%white: $75,80,62 \%$, respectively: Fisher's Exact test (FET), $p<0.39$ ), marital status (\%married: $17,24,15 \%$, respectively: FET, $p<0.21$ ), or income $(27000 \pm 1000,23000 \pm 700, \quad 29000 \pm 900, \quad$ respectively: $\mathrm{F}=0.28, \mathrm{df}=2, p<0.76)$. However, women outnumbered men, $12: 1$, in the MDE+PTSD group compared with a relatively even gender distribution in the MDE alone and HV groups $\left(\chi^{2}=14.7, p=0.001\right)$. In addition, compared to HV or MDE groups alone, the subjects with MDE+PTSD had fewer years of education $(17 \pm 2,16 \pm 2,14 \pm 2$, respectively: $\mathrm{F}=9.03, \mathrm{df}=2, p<0.00)$. Depression severity, presence of melancholia, suicide attempter status, rate of comorbid Cluster B personality disorders or history of childhood abuse, and severity of lifetime aggression or impulsivity were not different in the two patient groups. Patients in the MDE+PTSD group were more often psychotic (23\%) compared with the MDE group (2\%) (FET: $p=0.03$ ). Suicide attempters in each of the two patient groups did not differ in lethality, intent, number of suicide attempts, or severity of suicidal ideation (see Table 1).

Sex, suicide attempt status, number of suicide attempts, lethality of most severe suicide attempt, severity of depression as measured by HDRS and BDI, severity of anxiety, presence of childhood history of abuse, psychosis, and melancholia were found not to be predictors of baseline or postchallenge plasma cortisol. Furthermore, when we compared MDE subjects with psychosis to those without, psychotic subjects did not have significantly different cortisol levels $(p=0.12)$. Cortisol levels increased with age. Thus, the model was built using only lifetime diagnostic group and age as predictors. A general linear model showed that the MDE+PTSD group had the lowest levels of plasma cortisol over the $5 \mathrm{~h}$ of sampling, the MDE group had the highest plasma cortisol levels, and HVs had intermediate levels $(\mathrm{F}=10.11, p=0.001)$ (see Figure 1, note: data points on the figures are plotted twice for HV and MDE+PTSD groups to facilitate viewing of the error bars, which would otherwise overlap). When used in the model instead of the lifetime diagnostic group, the presence of current PTSD also had a similar significant effect on cortisol levels $(F=7.95$, $p=0.006)$. The shape of the curve of cortisol levels was similar in the three groups (see Figure 1). There was a significant increase in cortisol after fenfluramine administration in each of the three groups $(\mathrm{F}=6.04, p<0.001)$. There were no group differences in plasma cortisol responses to fenfluramine (see Figure 2). Group differences in plasma cortisol were present independent of the challenge condition. There were no group differences in fenfluramine plus norfenfluramine levels on the second study day $(\mathrm{F}=2.48, p=0.09)$, ruling out a pharmacokinetic effect. Neither severity of current depression as measured by BDI or HDRS ( $\mathrm{F}=0.01, p=0.92$ and $\mathrm{F}=2.55, p=0.11$, respectively) nor anxiety $(\mathrm{F}=3.88, p=0.053)$ had significant effects when added to the model that included age and lifetime diagnostic group as predictors.

\section{DISCUSSION}

We found that the group with MDE had the highest plasma cortisol levels and the group with MDE+PTSD had the lowest, with HVs having levels intermediate compared with the other two groups. Furthermore, there was a significant increase in cortisol after dl-fenfluramine administration in each of the three groups, but hormonal response to dlfenfluramine failed to discriminate between MDE,

Table I Clinical Characteristics of Patients with MDE and MDE \pm PTSD

\begin{tabular}{|c|c|c|c|c|c|}
\hline Variable name & $\begin{array}{l}\text { MDE }(n=45) \\
\text { Mean } \pm \text { SD (\%) }\end{array}$ & $\begin{array}{l}\text { MDE+PTSD }(n=13) \\
\text { Mean } \pm \text { SD }(\%)\end{array}$ & df & $\operatorname{tor}\left(\chi^{2}\right)$ & $P$ \\
\hline HDRS & $19.3 \pm 5.4$ & $21.8 \pm 6.1$ & 56 & -1.43 & 0.16 \\
\hline Beck depression scale & $28.1 \pm 9.3$ & $33.2 \pm 10.4$ & 53 & -1.69 & 0.10 \\
\hline Hopelessness scale & $12.7 \pm 4.5$ & $13.7 \pm 5.7$ & 53 & -0.64 & 0.52 \\
\hline Number of suicide attempts & $2.5 \pm 2.4$ & $4.1 \pm 4.3$ & 29 & -1.38 & 0.18 \\
\hline Maximum lethality of suicide attempts & $4.0 \pm 2.0$ & $5.3 \pm 2.4$ & 27 & -1.37 & 0.18 \\
\hline Scale of suicide ideation & $16.5 \pm 8.2$ & $14.7 \pm 12.2$ & 24 & 0.44 & 0.67 \\
\hline Brown-Goodwin aggression scale & $17.6 \pm 5.1$ & $18.9 \pm 5.5$ & 53 & -0.81 & 0.42 \\
\hline Barratt impulsivity scale & $53.7 \pm 16.7$ & $55.3 \pm 13.6$ & 49 & -0.29 & 0.77 \\
\hline Suicide intent scale & $16.5 \pm 5.2$ & $17.8 \pm 6.0$ & 28 & -0.56 & 0.58 \\
\hline Percent suicide attempters & $(48.9)$ & $(69.2)$ & & FET & 0.22 \\
\hline History of childhood abuse & $(42.9)$ & $(30.8)$ & & FET & 0.53 \\
\hline Presence of melancholia & $(28.9)$ & $(30.8)$ & & FET & 1.00 \\
\hline Cluster B personality disorder & $(36.4)$ & $(53.9)$ & & $(1.27)$ & 0.26 \\
\hline Presence of Psychosis & $(2.2)$ & $(23.1)$ & & FET & 0.03 \\
\hline
\end{tabular}




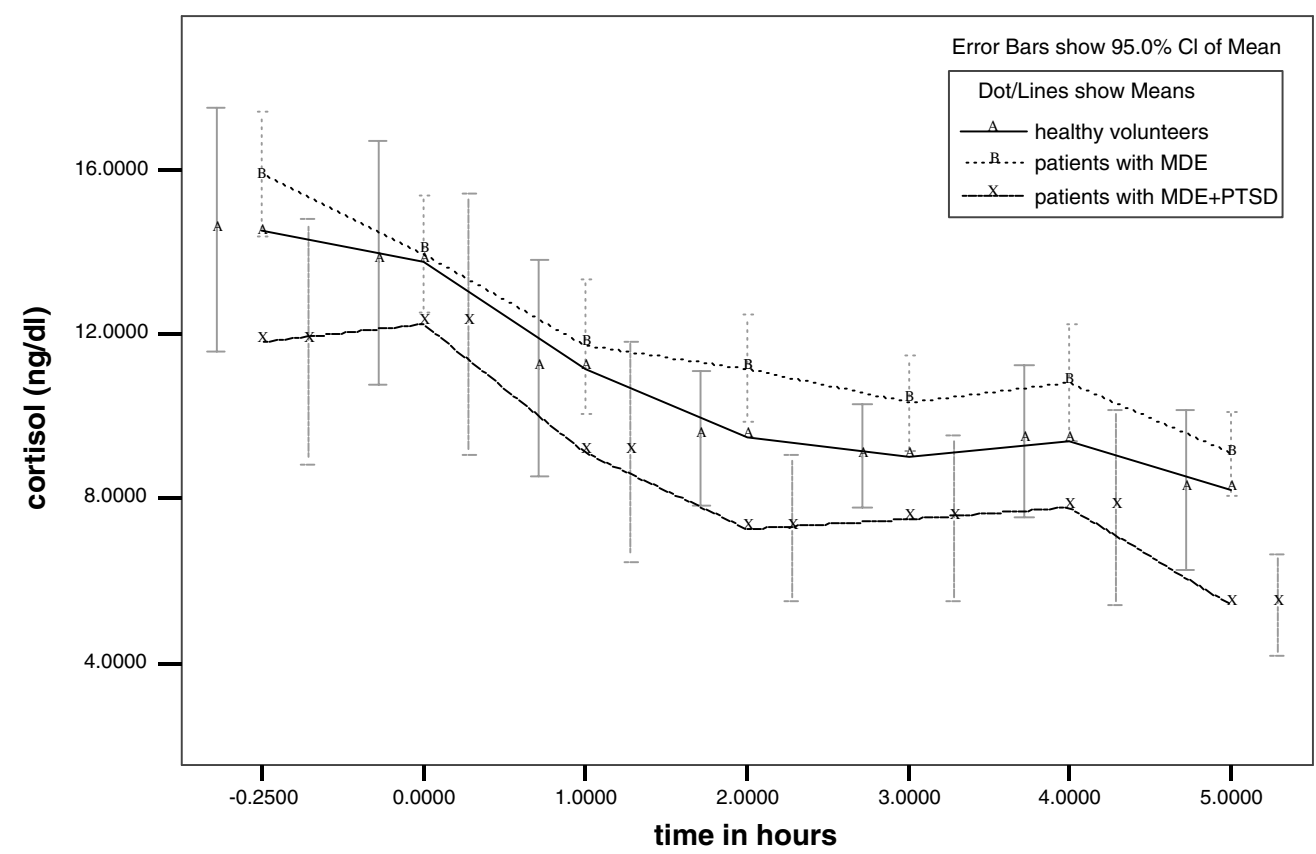

Figure I Plasma cortisol levels during placebo challenge in $\mathrm{HVs}$, patients with MDE, and patients with MDE+PTSD.

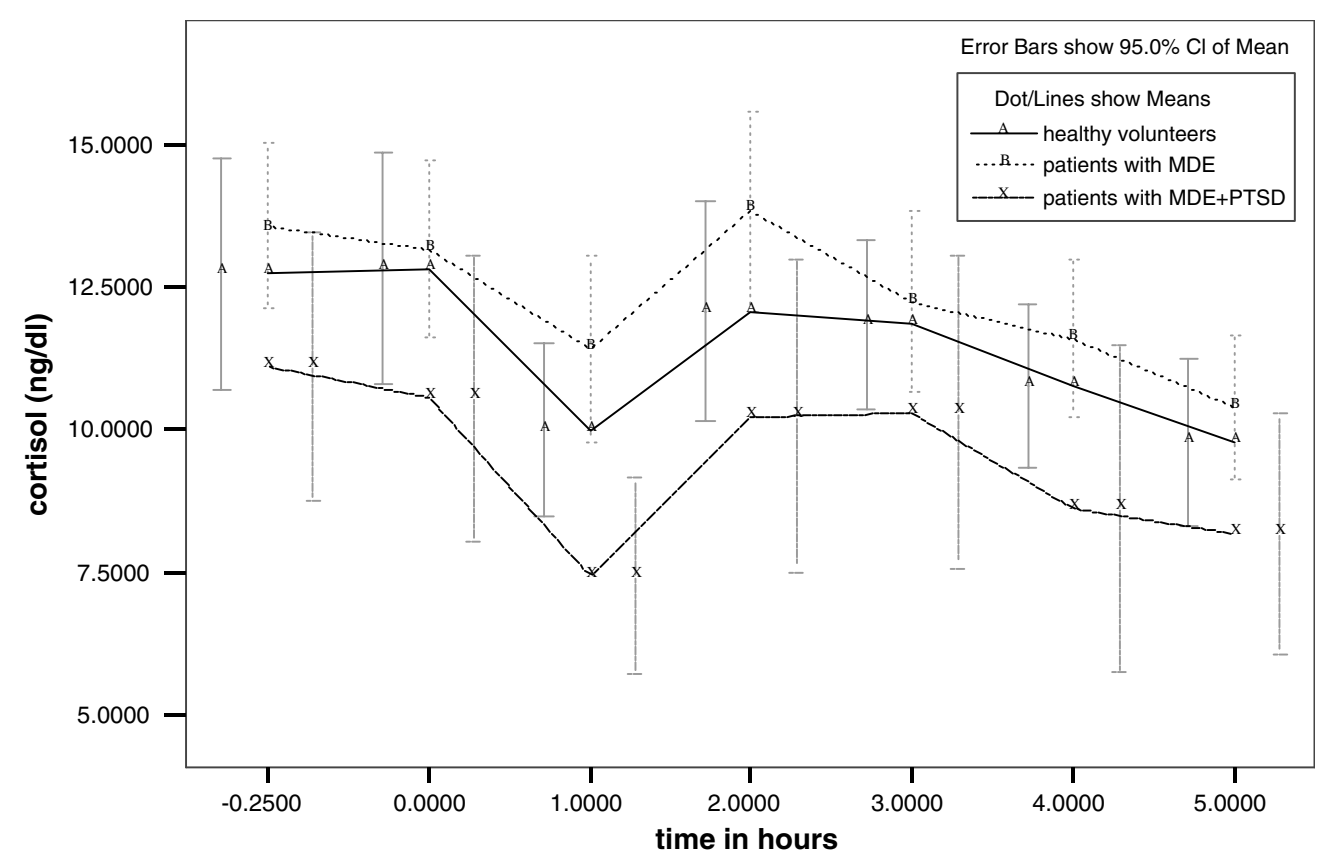

Figure 2 Plasma cortisol levels during fenfluramine challenge in HVS, patients with MDE, and patients with MDE+PTSD.

MDE+PTSD, and HVs. Cortisol levels increased with age as has been previously reported (Duval et al, 2001), but various parameters of suicidal behavior were unrelated to cortisol with or without dl-fenfluramine challenge. In addition, consistent with the literature regarding preponderance of female gender and low IQ in PTSD, we found that both female gender and less education were more common in the group with MDE+PTSD (Stein, 2001).

\section{HPA Function and Clinical Parameters}

We were unable to find evidence for the previously reported associations of HPA dysfunction and depression severity (Duval et al, 2001), psychosis (Duval et al, 2001), childhood history of abuse (Heim and Nemeroff, 2001), or melancholia (Brown et al, 1987). Whether this is reflective of methodological differences such as the use of cortisol response to fenfluramine, rather than urinary cortisol, ACTH challenge, 
or DST is not known. Furthermore, our patient sample may differ from those in other studies given the relatively high proportion of suicide attempters and patients with Cluster B personality disorder.

\section{HPA Axis Hypoactivity in PTSD+MDE}

Most studies of HPA function in PTSD have not made a direct comparison of depressed subjects with and without PTSD. Therefore, we discuss our findings in terms of what is reported in PTSD. Many studies have found lower plasma or 24-h urine cortisol in subjects with PTSD compared with normal controls (Yehuda et al, 1990) or MDE (Mason et al, 1986; Yehuda et al, 1996), and those at risk for PTSD such as victims of motor vehicle accidents (Delahanty et al, 2000), war veterans (Mason et al, 2001; Yehuda et al, 1995), and trauma victims (Yehuda et al, 2000). In addition, one study found lower 24-h urinary cortisol subjects with PTSD compared with controls, regardless of whether they had comorbid major depression (Yehuda et al, 1990). That finding is in agreement with our results and suggests that cortisol levels are low in comorbid MDE and PTSD as has been shown in PTSD alone. However, not all studies find low cortisol with PTSD alone (Liberzon et al, 1999; Pitman and Orr, 1990; Lemieux and Coe, 1995; Maes et al, 1999; Smith et al, 1989; Baker et al, 1999), perhaps because of subject selection, diagnostic criteria utilized, or other methodological issues. Although hypersuppression in response to dexamethasone has been reported in sexual abuse victims, most of whom had PTSD, compared to normal controls (Stein et al, 1997), normal suppression (Dinan et al, 1990; Halbreich et al, 1989) has also been reported. We did not measure plasma ACTH in response to fenfluramine. However, our findings are consistent with the postulated enhanced negative feedback inhibition of the HPA axis in PTSD (Yehuda, 2001). Increases in lymphocytic glucocorticoid receptors are reported in PTSD and trauma victims (Yehuda et al, 1991) and may underlie feedback supersensitivity via the hippocampus, and thereby lower plasma cortisol. We found a normal cortisol response to fenfluramine challenge in our subjects suggesting that pituitaryadrenal response to serotonin was normal and that the low cortisol levels are because of either suprapituitary factors such as enhanced feedback inhibition at the level of the hippocampus or adrenacorticol responses (Kanter et al, 2001).

\section{HPA Axis Hyperactivity in MDE}

The HPA axis in major depression has been studied extensively. Higher plasma cortisol levels are reported in MDE compared with HVs (Brown et al, 1987; Yehuda et al, 1990; Westrin et al, 1999). In total, 37-71\% of subjects in samples of MDE are nonsuppressors on the DST (Brown et al, 1987; Carroll, 1982; Stokes and Sikes, 1987). Our results are consistent with much of the literature in reporting HPA hyperactivity in subjects with depression, but demonstrate that a comorbid condition such as PTSD can profoundly affect HPA function in major depression. In this study, the depressed subjects with comorbid PTSD had plasma cortisol levels resembling those reported for PTSD alone and for MDE alone.
PTSD results from a traumatic previous experience. Heim et al (2001) reported that depressed women who reported a history of abuse in childhood had lower cortisol responses to ACTH than nonabused depressed women, and noted that the women who reported abuse during childhood had higher rates of PTSD than those who had not. In our study, the group with MDE and the group with MDE+PTSD did not differ in frequency of early childhood abuse, and presence of history of childhood abuse did not have a significant impact on cortisol levels. Whether some of the HPA abnormalities reported in abused populations are related to the neurobiological consequences of abuse and neglect, as has also been demonstrated in animal studies of maternal separation (Hofer, 1996; Viau et al, 1996; Heim and Nemeroff, 2001), or to the high rates of PTSD often observed in populations experiencing early childhood abuse requires further study. It is also unknown whether abuse experienced in childhood and in adulthood have different effects on the stress response and risk for later development of PTSD, or why only some subjects are vulnerable to the long-term biological and psychological effects of traumatic experiences.

\section{HPA Axis Hyperactivity and Suicidal Behavior}

Both PTSD and MDE are associated with a higher risk for suicidal behavior (Chen and Dilsaver, 1996; Davidson et al, 1991). Studies examining the risk of suicidal behavior in patients having PTSD and MDE (Kramer et al, 1994; Brady et al, 2000; Freeman et al, 2000; Shalev et al, 1998) report more suicidal ideation compared with PTSD or MDE alone. Perhaps because of the sample size, we did not find differences in the rate of suicide attempters, in the number of suicide attempts, or suicidal ideation of the attempters in the MDE+PTSD group compared to the MDE group. We also did not find a relation between attempter status, maximum lethality of suicide attempt, or number of suicide attempts and cortisol levels. Studies of the relation between suicidal behavior and HPA function often involve diagnostically heterogeneous populations (van Heeringen et al, 2000; Träskman-Bendz et al, 1992; Meltzer et al, 1984; Coryell and Schlesser, 2001; Brunner et al, 2001), but suggest that there is an association between suicidal behavior and hyperactivity of the HPA axis. The two most consistent findings regarding the HPA axis relate to violence of attempts and eventual suicide completion. Eventual suicides are reported to have higher cortisol levels after being administered dexamethasone than nonsuicides, and HPA axis hyperactivity at baseline may increase the odds of an eventual suicide as much as 14-fold (Coryell and Schlesser, 2001). Patients with a history of violent suicide attempt are reported to have higher levels of urinary free cortisol (van Heeringen et al, 2000), higher serum cortisol levels in response to 5HTP (Meltzer et al, 1984), and DST nonsuppression (Roy, 1992 ; Coryell and Schlesser, 2001), but no difference in CSF CRH (Träskman-Bendz et al, 1992) compared with patients without such history. Studies comparing suicide attempters to nonattempters, regardless of the method of suicide attempt, do not agree as to whether cortisol levels are elevated (Inder et al, 1997 ; Roy, 1992). Thus, the bulk of the studies published to date support the notion that there is a relation between suicide and HPA 
activity, but the results are unclear with regard to suicide attempts. These studies do not report on the presence of a history of abuse or trauma or rates of PTSD, perhaps because the studies were conducted prior to the recognition of the importance of PTSD as a diagnosis. Our findings do not detect a relation of suicidal behavior to HPA function regardless of comorbid PTSD. Our study groups included serious suicide attempters with mean medical lethality scores of at least 4 , reflecting a degree of physical injury requiring medical intervention. Thus, severity of suicide attempts is unlikely to explain why we did not find an association of suicide attempts to HPA function.

\section{Cortisol Response to Serotonin Release by Fenfluramine in MDE, MDE+PTSD, and HVs}

We found a significant increase in cortisol after dlfenfluramine administration in each of the three groups. However, the hormonal response to dl-fenfluramine failed to discriminate MDE or MDE+PTSD from HVs. There is disagreement as to whether the cortisol response to fenfluramine is altered in depressed subjects compared to healthy controls (Newman et al, 1998). Some evidence suggests an abnormality of serotonergic function in PTSD. A study of the prolactin response to fenfluramine suggests that subjects with PTSD (five of the eight male subjects had comorbid MDE) have a blunted response compared to normal controls (Davis et al, 1999). Some (Fichtner et al, 1995; Maes et al, 1999), but not all (Cicin-Sain et al, 2000; Maguire et al, 1998), reports regarding paroxetine binding to platelets suggest that binding is decreased in PTSD. Lower serotonin in platelet-poor plasma is reported in chronic PTSD although the frequency of comorbidity with MDE is not described (Spivak et al, 1999). The lack of difference in the cortisol responses of patients and HVs suggests that the ACTH response to fenfluramine is similar in the three groups. However, rodent and nonhuman primate studies show that animals that undergo early severe stress and show disrupted HPA function, as measured by high central CRH levels or elevated ACTH responses to stress, can still demonstrate normal peripheral glucocorticoid responses to acute stress (Heim and Nemeroff, 2001). Thus, we cannot exclude an alteration in ACTH or CRH regulation in our study. Consequently, it is possible that some effects on the HPA, such as those of suicidal behavior or childhood abuse, are at the level of the hypothalamus or pituitary, and not detectable with our methodology. Indeed, Smith et al (1989) demonstrated that Vietnam veterans with chronic PTSD showed a normal increase in cortisol despite lower ACTH response to CRH administration, and that this normal response of cortisol was present regardless of whether or not the subjects also had comorbid depression.

\section{CONCLUSIONS AND SUMMARY}

This study is the first to show that subjects with major depressive episode (MDE) and comorbid post-traumatic stress disorder (MDE+PTSD) have lower plasma cortisol levels than healthy volunteers (HVs), as has been reported previously for PTSD alone. The subjects with MDE alone had higher plasma cortisol levels than HVs. However, cortisol response to fenfluramine was the same in the three groups. This suggests that the abnormality in HPA function in depressed subjects with or without PTSD involves suprahypophyseal components or changes in adrenocorticol response. We were unable to find a relation between suicidal behavior or history of childhood abuse and plasma cortisol or cortisol response to fenfluramine. Further studies of the role of the HPA axis in PTSD and MDE may clarify the underlying mechanisms for these observations.

\section{REFERENCES}

American Psychiatric Association Task Force (1987). Diagnostic and Statistical Manual of Mental Disorders (DSM-III-R). APA Press: Washington, DC.

Baker DG, West SA, Nicholson WE, Ekhator NN, Kasckow JW, Hill KK et al (1999). Serial CSF corticotropin-releasing hormone levels and adrenocortical activity in combat veterans with posttraumatic stress disorder. Am J Psychiatry 156: 585-588.

Barratt ES (1965). Factor analysis of some psychometric measures of impulsiveness and anxiety. Psychol Rep 16: 547-554.

Beck AT, Beck R, Kovacs M (1975). Classification of suicidal behaviors: I. Quantifying intent and medical lethality. Am J Psychiatry 132: 285-287.

Beck AT, Kovacs M, Weissman A (1979). Assessment of suicidal intention: The scale for suicide ideation. J Consult Clin Psychol 47: 343-352.

Beck AT, Ward CH, Mendelson M, Mock J, Erbaugh J (1961). An inventory for measuring depression. Arch Gen Psychiatry 4: 53-63.

Brady KT, Killeen TK, Brewerton T, Lucerini S (2000). Comorbidity of psychiatric disorders and posttraumatic stress disorder. $J$ Clin Psychiatry 61(Suppl 7): 22-32.

Brown GL, Goodwin FK, Ballenger JC, Goyer PF, Major LF (1979). Aggression in human correlates with cerebrospinal fluid amine metabolites. Psychiatry Res 1: 131-139.

Brown ES, Rush AJ, McEwen BS (1999). Hippocampal remodeling and damage by corticosteroids: implications for mood disorders. Neuropsychopharmacology 21: 474-484.

Brown RP, Stoll PM, Stokes PE, Frances A, Sweeney JA, Kocsis JH et al (1987). Adrenocortical hyperactivity in depression: effects of agitation, delusions, melancholia, and other illness variables. Psychiatry Res 23: 167-178.

Brunner J, Stalla GK, Stalla J, Uhr M, Grabner A, Wetter TCl et al (2001). Decreased corticotropin-releasing hormone (CRH) concentrations in the cerebrospinal fluid of eucortisolemic suicide attempters. J Psychiatr Res 35: 1-9.

Carroll BJ (1982). The dexamethasone suppression test for melancholia. Br J Psychiatry 140: 292-304.

Chen Y-W, Dilsaver SC (1996). Lifetime rates of suicide attempts among subjects with bipolar and unipolar disorders relative to subjects with other axis I disorders. Biol Psychiatry 39: 896-899.

Cicin-Sain L, Mimica N, Hranilovic D, Balija M, Ljubin T, Makaric $\mathrm{G}$ et al (2000). Posttraumatic stress disorder and platelet serotonin measures. J Psychiatr Res 34: 155-161.

Cleare AJ, Murray RM, O'Keane V (1996). Reduced prolactin and cortisol responses to d-fenfluramine in depressed compared to healthy matched control subjects. Neuropsychopharmacology 14: 349-354.

Coryell W, Schlesser M (2001). The dexamethasone suppression test and suicide prediction. Am J Psychiatry 158: 748-753.

Davidson JRT (1995). Posttraumatic stress disorder and acute stress disorder. In: Kaplan HI, Sadock BJ (eds). Comprehensive 
Textbook of Psychiatry/VI, 6th edn. Williams \& Wilkins, A Waverly Company: Baltimore. pp 1227-1236.

Davidson JR, Hughes D, Blazer DG, George LK (1991). Posttraumatic stress disorder in the community: an epidemiological study. Psychol Med 21: 713-721.

Davis LL, Clark DM, Kramer GL, Moeller FG, Petty F (1999). Dfenfluramine challenge in posttraumatic stress disorder. Biol Psychiatry 45: 928-930.

Delahanty DL, Raimonde AJ, Spoonster E (2000). Initial posttraumatic urinary cortisol levels predict subsequent PTSD symptoms in motor vehicle accident victims. Biol Psychiatry 48: 940-947.

Dinan TG, Barry S, Yatham LN, Mobayed M, Brown I (1990). A pilot study of a neuroendocrine test battery in posttraumatic stress disorder. Biol Psychiatry 28: 665-672.

Duval F, Mokrani MC, Correa H, Bailey P, Valdebenito M, Monreal $\mathrm{J}$ et al (2001). Lack of effect of HPA axis hyperactivity on hormonal responses to d-fenfluramine in major depressed patients: implications for pathogenesis of suicidal behaviour. Psychoneuroendocrinology 26: 521-537.

Fichtner CG, O'Connor FL, Yeoh HC, Arora RC, Crayton JW (1995). Hypodensity of platelet serotonin uptake sites in posttraumatic stress disorder: associated clinical features. Life Sci 57: L37-L44.

First MB, Spitzer RL, Gibbon M, Williams JMG, Benjamin L (1996). Structured Clinical Interview for DSM-IV Axis II Personality Disorders (SCID-II), Version 2.0. Biometrics Research Department, New York State Psychiatric Institute: New York.

Freeman TW, Roca V, Moore WM (2000). A comparison of chronic combat-related posttraumatic stress disorder (PTSD) patients with and without a history of suicide attempt. J Nerv Ment Dis 188: 460-463.

Halbreich U, Olympia J, Carson S, Glogowski J, Yeh CM, Axelrod S (1989). Hypothalamo-pituitary-adrenal activity in endogenously depressed post-traumatic stress disorder patients. Psychoneuroendocrinology 14: 365-370.

Hamilton M (1960). A rating scale for depression. J Neurol Neurosurg Psychiatry 23: 56-62.

Heim C, Nemeroff CB (2001). The role of childhood trauma in the neurobiology of mood and anxiety disorders: preclinical and clinical studies. Biol Psychiatry 49: 1023-1039.

Heim C, Newport DJ, Bonsall R, Miller AH, Nemeroff CB (2001). Altered pituitary-adrenal axis responses to provocative challenge tests in adult survivors of childhood abuse. $A m J$ Psychiatry 158: 575-581.

Hofer MA (1996). On the nature and consequences of early loss. Psychosom Med 58: 570-581.

Inder WJ, Donald RA, Prickett TC, Frampton CM, Sullivan PF, Mulder RT et al (1997). Arginine vasopressin is associated with hypercortisolemia and suicide attempts in depression. Biol Psychiatry 42: 744-747.

Kanter ED, Wilkinson CW, Radant AD, Petrie EC, Dobie DJ, McFall ME et al (2001). Glucocorticoid feedback sensitivity and adrenocortical responsiveness in posttraumatic stress disorder. Biol Psychiatry 50: 238-245.

Kramer TL, Lindy JD, Green BL, Grace MC, Leonard AC (1994). The comorbidity of post-traumatic stress disorder and suicidality in Vietnam veterans. Suicide Life Threat Behav 24: 58-67.

Krebs HA, Cheng LK, Wright GJ (1984). Determination of fenfluramine and norfenfluramine in plasma using a nitrogensensitive detector. J Chromatogr Biomed Appl 310: 412-417.

Lemieux AM, Coe CL (1995). Abuse-related posttraumatic stress disorder: evidence for chronic neuroendocrine activation in women. Psychosom Med 57: 105-115.

Lesch KP, Mayer S, Disselkamp-Tietze J, Hoh A, Wiesmann M, Osterheider $\mathrm{M}$ et al (1990). 5- $\mathrm{HT}_{1 \mathrm{~A}}$ receptor responsivity in unipolar depression: evaluation of ipsapirone-induced ACTH and cortisol secretion in patients and controls. Biol Psychiatry 28: $620-628$.
Liberzon I, Abelson JL, Flagel SB, Raz J, Young EA (1999). Neuroendocrine and psychophysiologic responses in PTSD: a symptom provocation study. Neuropsychopharmacology 21: 4050.

Maes M, Lin AH, Verkerk R, Delmeire L, Van Gastel A, Van der PM et al (1999). Serotonergic and noradrenergic markers of post-traumatic stress disorder with and without major depression. Neuropsychopharmacology 20: 188-197.

Maes M, Mylle J, Delmeire L, Altamura C (2000). Psychiatric morbidity and comorbidity following accidental man-made traumatic events: incidence and risk factors. Eur Arch Psychiatry Clin Neurosci 250: 156-162.

Magarinos AM, McEwen BS (1995). Stress-induced atrophy of apical dendrites of hippocampal CA3c neurons: comparison of stressors. Neuroscience 69: 83-88.

Maguire K, Norman T, Burrows G, Hopwood M, Morris P (1998). Platelet paroxetine binding in post-traumatic stress disorder. Psychiatry Res 77: 1-7.

Mason JW, Giller EL, Kosten TR, Ostroff RB, Podd L (1986). Urinary free-cortisol levels in posttraumatic stress disorder patients. J Nerv Ment Dis 174: 145-149.

Mason JW, Wang S, Yehuda R, Riney S, Charney DS, Southwick SM (2001). Psychogenic lowering of urinary cortisol levels linked to increased emotional numbing and a shame-depressive syndrome in combat-related posttraumatic stress disorder. Psychosom Med 63: 387-401.

Meijer OC, De Kloet ER (1998). Corticosterone and serotonergic neurotransmission in the hippocampus: functional implications of central corticosteriod receptor diversity. Crit Rev Neurobiol 12: $1-20$.

Meltzer HY, Perline R, Tricou BJ, Lowy M, Robertson A (1984). Effect of 5-hydroxytryptophan on serum cortisol levels in major affective disorders. II. Relation to suicide, psychosis and depressive symptoms. Arch Gen Psychiatry 41: 379-387.

Myers JE, Mieczkowski TA, Perel J, Abbondanza DM, Cooper TB, Mann JJ (1994). Abnormal behavioral responses to fenfluramine in patients with affective and personality disorders: correlation with increased serotonergic responsivity. Biol Psychiatry 35: $112-120$

Newman ME, Shapira B, Lerer B (1998). Evaluation of central serotonergic function in affective and related disorders by the fenfluramine challenge test: a critical review. Int J Neuropsychopharmcol 1: 49-69.

Norman WH, Brown WA, Miller IW, Keitner GI, Overholser JC (1990). The dexamethasone suppression test and completed suicide. Acta Psychiatr Scand 81: 120-125.

Oei TI, Verhoeven WM, Westenberg HG, Zwart FM, Van Ree JM (1990). Anhedonia, suicide ideation and dexamethasone nonsuppression in depressed patients. J Psychiatr Res 24: 25-35.

Overall JE, Gorham DR (1962). The brief psychiatric rating scale. Psychol Rep 10: 799-812.

Pitman RK, Orr SP (1990). Twenty-four hour urinary cortisol and catecholamine excretion in combat-related posttraumatic stress disorder. Biol Psychiatry 27: 245-247.

Reist C, Kauffmann CD, Chicz-DeMet A, Chen CC, DeMet EM (1995). REM latency, dexamethasone suppression test, and thyroid releasing hormone stimulation test in posttraumatic stress disorder. Prog Neuropsychopharmacol Biol Psychiatry 19: 433-443.

Roy A (1992). Hypothalamic-pituitary-adrenal axis function and suicidal behavior in depression. Biol Psychiatry 32: 812-816.

Shalev AY, Freedman S, Peri T, Brandes D, Sahar T, Orr SP et al (1998). Prospective study of posttraumatic stress disorder and depression following trauma. Am J Psychiatry 155: 630-637.

Smith MA, Davidson J, Ritchie JC, Kudler H, Lipper S, Chappell P et al (1989). The corticotropin-releasing hormone test in patients with posttraumatic stress disorder. Biol Psychiatry 26: 349-355. 
Spivak B, Vered Y, Graff E, Blum I, Mester R, Weizman A (1999). Low platelet-poor plasma concentrations of serotonin in patients with combat-related posttraumatic stress disorder. Biol Psychiatry 45: $840-845$.

Stein MB (2001). Psychopharmacology of acute stress and post traumatic stress disorder: prevention and treatment. ACNP 40th Annual Meeting, Kona, Hawaii.

Stein MB, Yehuda R, Koverola C, Hanna C (1997). Enhanced dexamethasone suppression of plasma cortisol in adult women traumatized by childhood sexual abuse. Biol Psychiatry 42: 680686.

Stokes PE, Sikes CR (1987). Hypothalamic-pituitary-adrenal axis in affective disorders. In: Meltzer HY (ed). Psychopharmacology: The Third Generation of Progress. Raven Press: New York. pp 589-607.

Träskman-Bendz L, Ekman R, Regnell G, Öhman R (1992). HPArelated CSF neuropeptides in suicide attempters. Eur Neuropsychopharmacol 2: 99-106.

van Heeringen K, Audenaert K, Van de WL, Verstraete A (2000). Cortisol in violent suicidal behaviour: association with personality and monoaminergic activity. J Affect Disord 60: 181-189.

Viau V, Sharma S, Meaney MJ (1996). Changes in plasma adrenocorticotropin, corticosterone, corticosteroid-binding globulin, and hippocampal glucocorticoid receptor occupancy/ translocation in rat pups in response to stress. J Neuroendocrinol 8: $1-8$.

Watanabe Y, Sakai RR, McEwen BS, Mendelson S (1993). Stress and antidepressant effects on hippocampal and cortical 5-HT1A and 5-HT2 receptors and transport sites for serotonin. Brain Res 615: 87-94.

Westrin A, Ekman R, Traskman-Bendz L (1999). Alterations of corticotropin releasing hormone $(\mathrm{CRH})$ and neuropeptide Y (NPY) plasma levels in mood disorder patients with a recent suicide attempt. Eur Neuropsychopharmacol 9: 205-211.

Yehuda R (2001). Current status of cortisol findings in PTSD. Psychiatric Clin North Am 25: 341-368.

Yehuda R, Bierer LM, Schmeidler J, Aferiat DH, Breslau I, Dolan S (2000). Low cortisol and risk for PTSD in adult offspring of holocaust survivors. Am J Psychiatry 157: 1252-1259.

Yehuda R, Boisoneau D, Lowy MT, Giller Jr EL (1995). Doseresponse changes in plasma cortisol and lymphocyte glucocorticoid receptors following dexamethasone administration in combat veterans with and without posttraumatic stress disorder. Arch Gen Psychiatry 52: 583-593.

Yehuda R, Lowy MT, Southwick SM, Shaffer D, Giller Jr EL (1991). Lymphocyte glucocorticoid receptor number in posttraumatic stress disorder. Am J Psychiatry 148: 499-504.

Yehuda R, Southwick SM, Nussbaum G, Wahby V, Giller Jr EL, Mason JW (1990). Low urinary cortisol excretion in patients with posttraumatic stress disorder. J Nerv Ment Dis 178: 366369.

Yehuda R, Teicher MH, Trestman RL, Levengood RA, Siever LJ (1996). Cortisol regulation in posttraumatic stress disorder and major depression: a chronobiological analysis. Biol Psychiatry 40: 79-88. 